\title{
BCR/ABL1 Fusion Negative
}

National Cancer Institute

\section{Source}

National Cancer Institute. BCR/ABL1 Fusion Negative. NCI Thesaurus. Code C128834.

Indicates that expression of the BCR/ABL1 fusion has not been detected in a sample. 